\title{
Integrated compensation model using a three-phase neutral point clamped inverter
}

\author{
Chau Minh Thuyen ${ }^{1}$, Nguyen Hoai Thuong ${ }^{2}$, Truong Khac Tung ${ }^{3}$ \\ ${ }^{1,2}$ Faculty of Electrical Engineering Technology, Industrial University of Ho Chi Minh City, Vietnam \\ ${ }^{3}$ Faculty of Information Technology, Industrial University of Ho Chi Minh City, Vietnam
}

\begin{tabular}{l} 
Article Info \\
\hline Article history: \\
Received Oct 28, 2019 \\
Revised Apr 16, 2020 \\
Accepted Apr 26, 2020 \\
\hline
\end{tabular}

Keywords:

Active compensation model Passive power filter Integrated compensation Nonlinear load Three-level NPC inverter

\begin{abstract}
Normally, when research on active compensation models, previous studies only assumed that the source of harmonics is nonlinear load. The nonlinear load here is fixed and balanced, the supply voltage is considered ideal, i.e. the three-phase source is balanced and there is no distortion. However, in reality, the above assumption is difficult to achieve. Therefore, this paper aims to design an integrated compensation model for different types of harmonic sources. The types of harmonic sources considered here include: harmonic sources generated from nonlinear load and source. The requirement of the integrated compensation model is to create a balanced three-phase voltage at the terminal of the load and the supply current must be a sinusoidal wave in phase with the source voltage. In order to reduce the loss caused by the inverter switching, this paper uses a three-level Neutral Point Clamped inverter. The simulation results performed on Psim software have demonstrated the effectiveness of the proposed integrated compensation model compared to the traditional integrated compensation model in reducing harmonics and stabilizing DC-bus voltage.
\end{abstract}

Copyright $\left({ }_{0} 2020\right.$ Institute of Advanced Engineering and Science. All rights reserved.

\section{Corresponding Author:}

Chau Minh Thuyen,

Faculty of Electrical Engineering Technology,

Industrial University of Ho Chi Minh City,

12 Nguyen Van Bao Road, Ward 4, Go Vap District, Ho Chi Minh City 700000, Vietnam.

Email: chauminhthuyen@iuh.edu.vn

\section{INTRODUCTION}

In industry, due to the nature and characteristics of the nonlinear load are generates harmonics and consumes a large amount of reactive power. Therefore, the issue of harmonic filtering and reactive power compensation has been a special concern of countries on the world. In order to cancel harmonics and compensate for reactive power, Passive Power Filter (PPF) in the form of the inductor $L$ in series with capacitor $C$ are commonly used [1,2]. However, PPFs have the main drawback that it is easy to resonate with the system impedance, compensation is not flexible. In order to improve the defects of PPF, the Active Power Filter (APF) [3-6] was born in the late 1970s. APF is often connected in parallel with nonlinear load to eliminate harmonic components of load and compensate reactive power. The biggest advantage of APF is its ability to compensate flexibly under the load, without resonance with the impedance of the grid. However, APF also has many shortcomings such as high cost, low capacity and difficult to use in high voltage grids. To improve these shortcomings, the Hybrid Active Power Filter (HAPF) [7-10] was born as a necessity. The structure of HAPF is a combination of PPFs and APF.

However, recent studies on HAPF have considered only harmonic sources generated by nonlinear loads and the source is ideal (balanced and non-distorted) [11-16]. In fact, the source of harmonics may be from nonlinear loads and also from sources. The source voltage can also be unbalanced and distorted. The nonlinear load can also be balanced or unbalanced, the load can change or not change. As a result, 
it makes the source voltage put on the load as unbalanced and distorted, the three-phase supply current will not be ideal and balanced, resulting HAPF work in less efficient. Moreover, traditional active compensation models only use two-level voltage source inverter [17-20]. Therefore, it will generate harmonics on the grid due to the switching process of the inverter. All of the above will reduce the working efficiency of the HAPF [21-23]. Based on this, this paper aims to introduce an integrated compensation model for different types of harmonic sources using a three-level Neutral Point Clamped (NPC) inverter to reduce switching losses and reduce ripple in the output of the inverter.

In this paper, the harmonic source is assumed to be generated from the nonlinear load and from source. The simulation results are carried out in two cases: the ideal and not ideal source while the load is also adjusted to change in the direction of increasing the total harmonic distortion (THD). The requirement is to ensure that the current and the voltage applied to the load in all cases are always in the sinusoidal wave in phase with the source voltage and have the lowest total harmonic distortion, meeting IEEE -519. [24]. In addition, stabilizing the DC bus voltage of the inverter is also a consideration. The proposed integrated compensation model must have a shorter dynamic response time and the voltage ripple on the DC-bus must also be smaller than the traditional integrated compensation model [25]. To demonstrate the effectiveness of the proposed model. The simulations were performed on two models: the integrated compensation model using a two-level voltage source inverter and the proposed model. Simulation results have demonstrated that: the proposed model is more effective in stabilizing DC-bus voltage and minimum the supply current total harmonic distortion, minimum the voltage total harmonic distortion applied to the load.

The paper consists of four parts: Part 1 gives an overview of the harmonic filter models and the urgency of the research problem, the integrated compensation model for different types of harmonic sources using a three-level NPC inverter is presented in part 2, the control of the proposed integrated compensation model given in part 3, part 4 is the simulation and discussion results, and part 5 is a summary of the achieved results.

\section{INTEGRATED COMPENSATION MODEL FOR DIFFERENT TYPES OF HARMONIC SOURCES USING A THE THREE-LEVEL NPC INVERTER}

The integrated compensation model for different types of harmonic sources using a three-level NPC Inverter is shown in Figure 1. Where $u_{s}$ is source voltage, $Z_{s}$ is impedance of source, $C_{P}$ and $L_{P}$ are inductance and capacitance of the passive power filter, $i_{P F}$ is the current through the passive power filter and $i_{L}$ is the load current. The single-phase harmonic equivalent circuit of proposed integrated compensation model is shown in Figure 2.

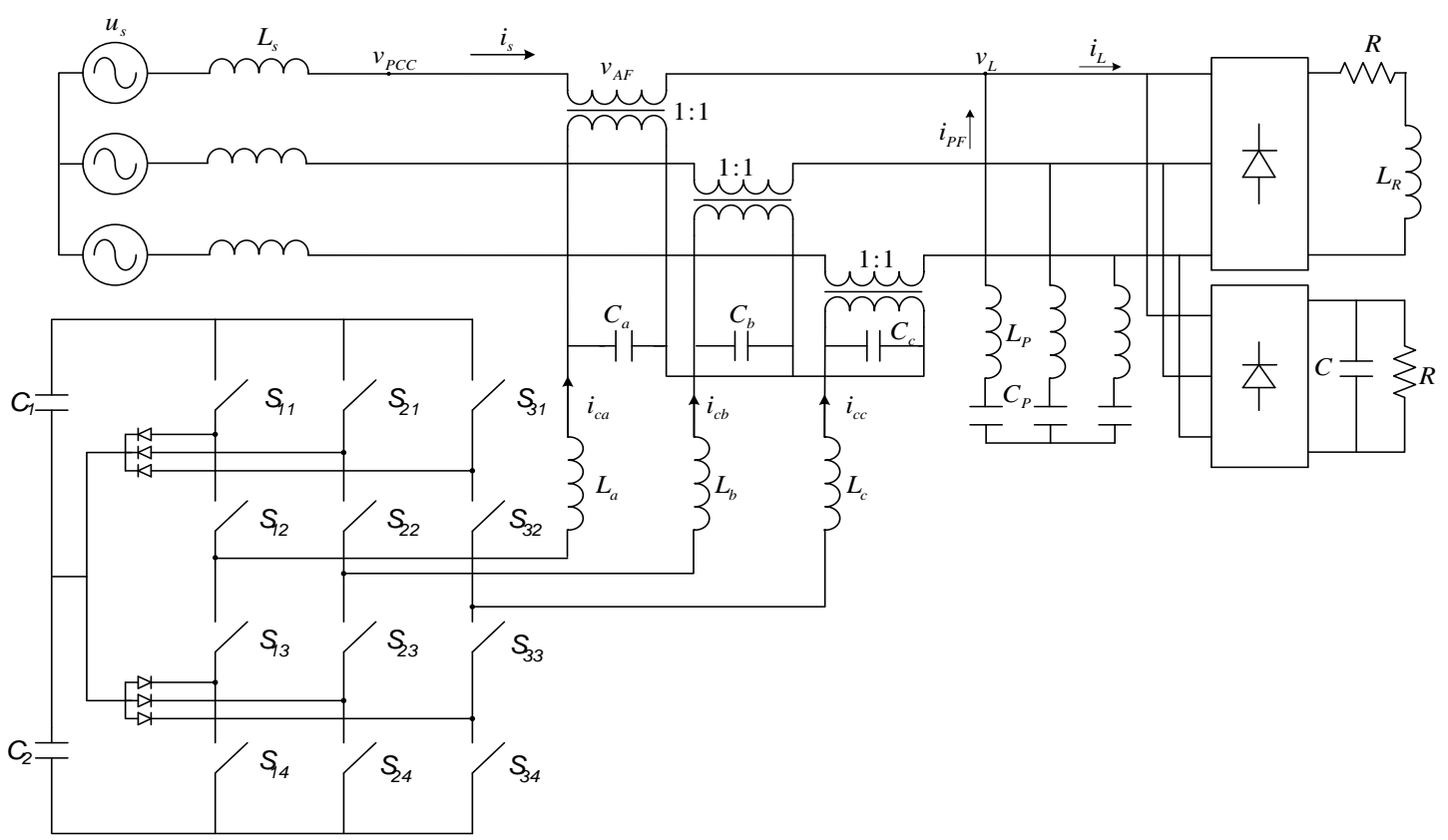

Figure 1. Proposed integrated compensation model 
The principle of operation of the circuit can be summarized as follows: passive power filters will eliminate the order high harmonic components of the load, the remaining harmonic components will be eliminated by the active circuit part. The purpose of the active circuit part is to provide a compensation voltage $v_{A F}$ proportional to the source harmonic current $i_{s h}$ through an active resistor $R_{a}$. Thus $R_{a}$ is considered as an active resistor at the harmonic components of the source harmonic current, and it is expressed by the following formula:

$$
v_{A F}=R_{a} \sum i_{s h}
$$

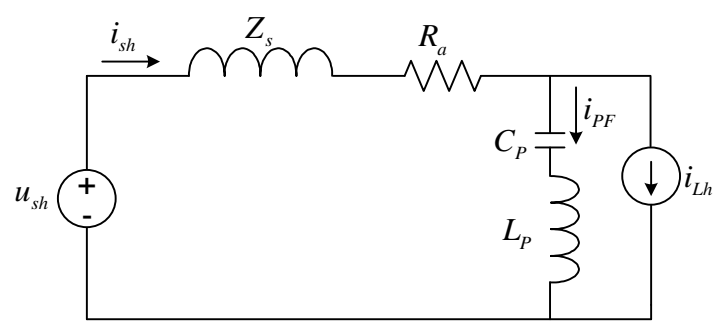

Figure 2. Single phase equivalent circuit for harmonic components of integrated compensation model

According to Figure 2, we have:

$$
I_{s h}=\frac{U_{s h}+Z_{P F} I_{L h}}{Z_{s h}+Z_{P F}+R_{a}}
$$

From (2), we can see that when the value of the active resistance $R_{a}$ increases, the amplitude of the current harmonic component decreases, and it prevents harmonic components from the source. As a result, the supply current becomes more balanced and near with the sinusoidal wave, the voltage applied to the load is always balanced and with a small total harmonic distortion.

\section{CONTROL FOR INTEGRATED COMPENSATION MODEL FOR DIFFERENT TYPES OF HARMONIC SOURCES}

Control diagram of integrated compensation model for different types of harmonic sources is shown in Figure 3. Starting from the three-phase supply current and source voltage through Clark and Park transformations [16] to convert from $a, b, c$ rotation coordinate to $p, q$ stationary coordinate and calculate active and reactive current components $i_{p}$ and $i_{q}$ follows the formula (3).

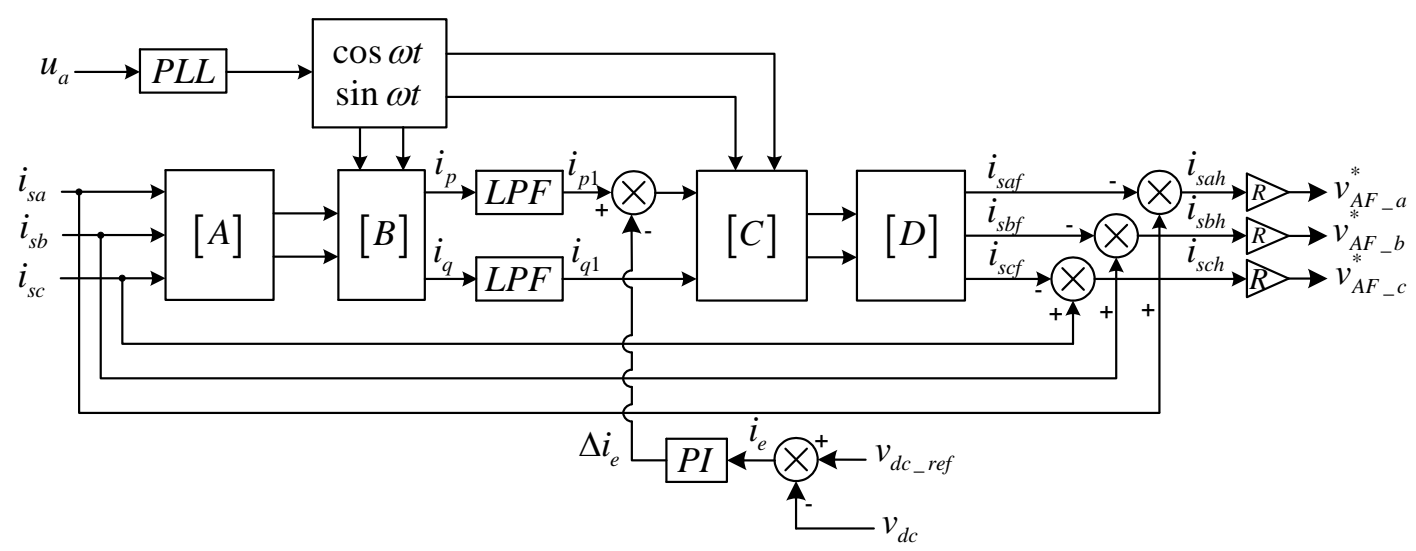

Figure 3. Control diagram of integrated compensation model for different types of harmonic sources 


$$
\left[\begin{array}{l}
i_{p} \\
i_{q}
\end{array}\right]=[A] \cdot[C] \cdot\left[\begin{array}{l}
i_{s a} \\
i_{s b} \\
i_{s c}
\end{array}\right]
$$

where: $[A]=\sqrt{\frac{2}{3}}\left[\begin{array}{ccc}1 & -\frac{1}{2} & -\frac{1}{2} \\ 0 & \sqrt{\frac{3}{2}} & -\sqrt{\frac{3}{2}}\end{array}\right] ;[C]=\left[\begin{array}{ll}\sin \omega_{1} t & -\cos \omega_{1} t \\ \cos \omega_{1} t & -\sin \omega_{1} t\end{array}\right]$

where: $[B]=\sqrt{\frac{2}{3}}\left[\begin{array}{rr}1 & 0 \\ -\frac{1}{2} & \sqrt{\frac{3}{2}} \\ -\frac{1}{2} & -\sqrt{\frac{3}{2}}\end{array}\right] ;[D]=\left[\begin{array}{lr}\sin \omega_{1} t & \cos \omega_{1} t \\ -\cos \omega_{1} t & -\sin \omega_{1} t\end{array}\right]$

From here, the harmonic supply current components are defined as:

$$
\left[\begin{array}{l}
i_{s a h} \\
i_{s b h} \\
i_{s c h}
\end{array}\right]=\left[\begin{array}{l}
i_{s a} \\
i_{s b} \\
i_{s c}
\end{array}\right]-\left[\begin{array}{l}
i_{s a f} \\
i_{s b f} \\
i_{s c f}
\end{array}\right]
$$

The reference compensation voltage:

$$
\left[\begin{array}{l}
v_{A F_{-} a}^{*} \\
v_{A F_{-} b}^{*} \\
v_{A F_{-} c}^{*}
\end{array}\right]=[R]\left[\begin{array}{l}
i_{s a h} \\
i_{s b h} \\
i_{s c h}
\end{array}\right]
$$

The reference compensation voltage value will be compared with the actual voltage measured at the compensation transformer on the grid. The error between these two values will be passed to the controller, the pulse generator to trigger the switching of the three-level neutral point clamped inverter. The pulse control circuit for the three-level neutral point clamped inverter is shown in Figure 4. 


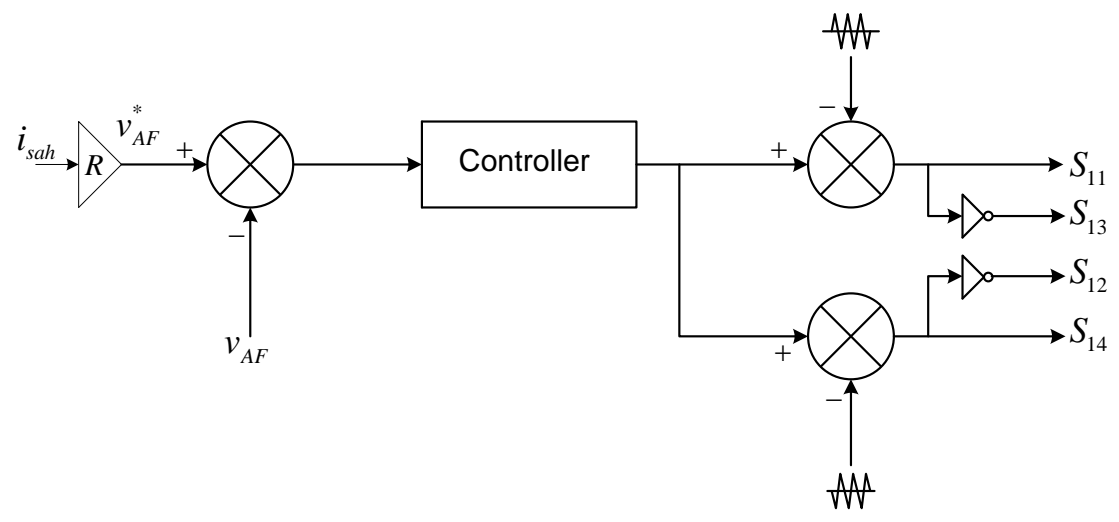

Figure 4. Pulse control circuit for three-level neutral point clamped inverter

\section{SIMULATION AND DISCUSSION RESULTS}

To prove the effectiveness of the proposed model. The simulations were performed on two models: the integrated compensation model using a two-level voltage source inverter and the integrated compensation model using a three-level NPC Inverter. The parameters of the model are given in Table 1. In the period of $0 \mathrm{~s} \div 0.5 \mathrm{~s}$, the three-phase load is balanced and has the THD value as shown in Figure 5. At the time $t=0.5 \mathrm{~s}$ the load is changed. The THD value of the load current after modification is shown in Figure 6.

Table 1. Parameters of the model in Figure 1

\begin{tabular}{ccccccccccc}
\hline $\begin{array}{c}L_{s} \\
(\mathrm{mH})\end{array}$ & $\begin{array}{c}C_{a} \\
(\mu \mathrm{F})\end{array}$ & $\begin{array}{c}L_{a} \\
(\mathrm{mH})\end{array}$ & $\begin{array}{c}C_{1} \\
(\mu \mathrm{F})\end{array}$ & $\begin{array}{c}C_{2} \\
(\mu \mathrm{F})\end{array}$ & $\begin{array}{c}R_{L} \\
(\Omega)\end{array}$ & $\begin{array}{c}L_{L} \\
(\mathrm{mH})\end{array}$ & $\begin{array}{c}R \\
(\Omega)\end{array}$ & $\begin{array}{c}C \\
(\mu \mathrm{F})\end{array}$ & $\begin{array}{c}C_{P} \\
(\mu \mathrm{F})\end{array}$ & $\begin{array}{c}L_{P} \\
(\mathrm{mH})\end{array}$ \\
\hline 0.2 & 60 & 3 & 4000 & 4000 & 20 & 30 & 50 & 500 & 600 & 16.89 \\
\hline
\end{tabular}

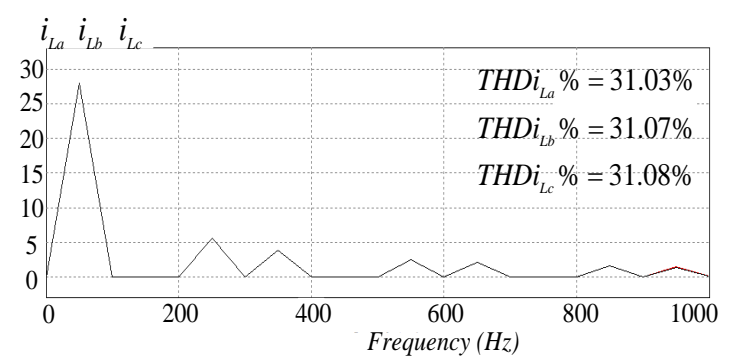

Figure 5. Frequency spectrum of load before changed



Figure 6. Frequency spectrum of load after changed

When the source voltage is balanced and no distortion, we have the waveforms of the integrated compensation model using a three-level NPC inverter shown in Figure 7 and the integrated compensation model using a two-level voltage source inverter shown in Figure 8. From Figure 7 we can see that: before the load changed, the three-phase supply current is balanced and has a THD value of $1.56 \%$, the source voltage applied to the load is balanced with a THD\% value of $2.2 \%$. When the load changes in the direction of increasing THD, the three-phase supply current is also balanced and has a THD\% value of $1.9 \%$ the voltage applied to the load is also balanced three-phase with a THD\% value of 3.8\%, DC-bus voltage reaches the set value of $300 \mathrm{~V}$ at $0.07 \mathrm{~s}$ before the load is changed and $0.04 \mathrm{~s}$ after the load is changed.

From Figure 8, we can see that: before the load changed, the three-phase supply current is balanced and has a THD\% value of $1.7 \%$, the source voltage applied to the load is also balanced three-phase with the THD\% value is $2.3 \%$. When the load change in the direction of increasing THD, the three-phase supply current is also balanced and has a THD\% value of $2.2 \%$, the source voltage applied to the load is also balanced three-phase with a THD\% value of $4.3 \%$, DC-bus voltage reaches the setting of $300 \mathrm{~V}$ at $0.15 \mathrm{~s}$ before load changed and $0.04 \mathrm{~s}$ after load changed. 


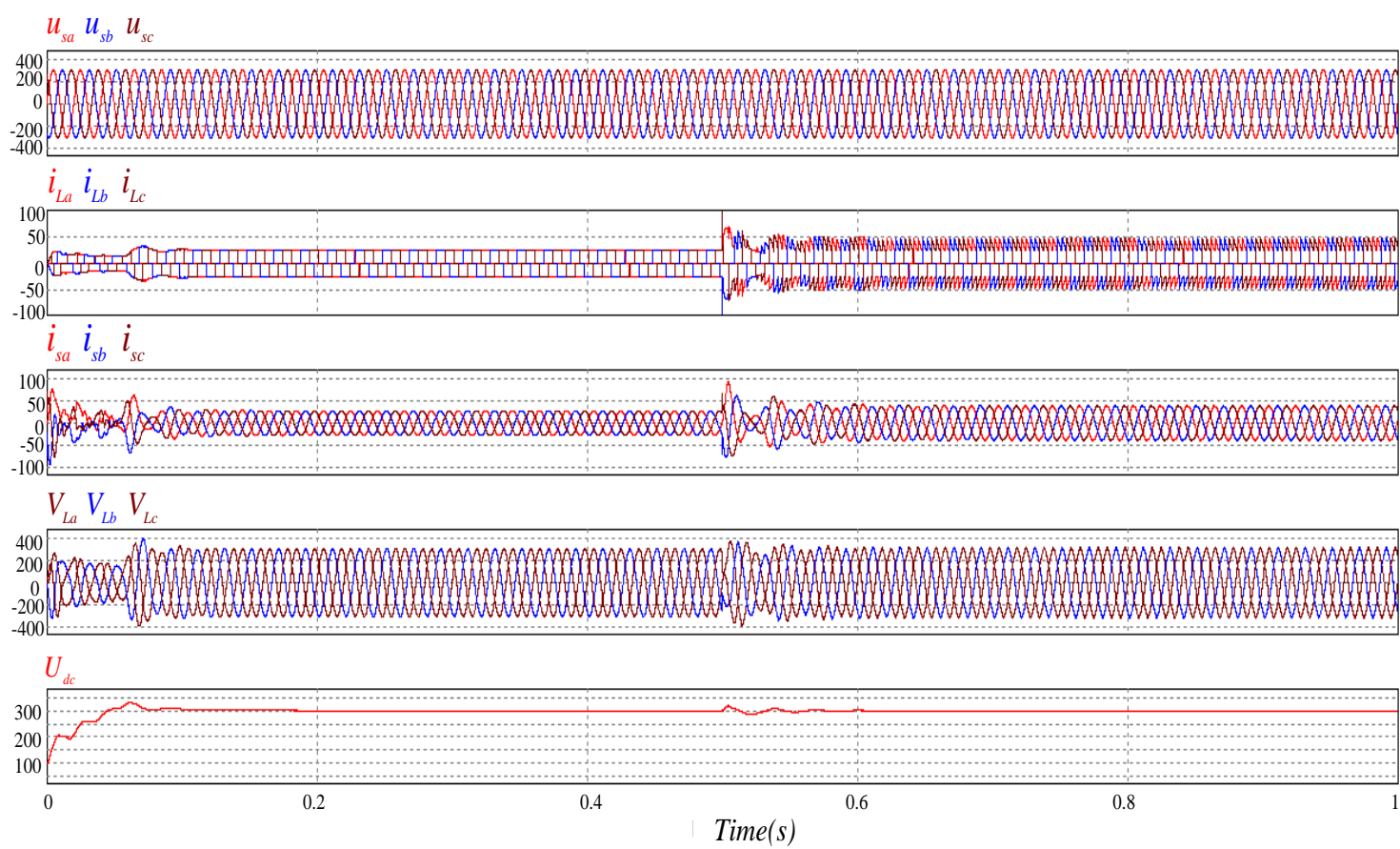

Figure 7. Waveforms of the proposed integrated compensation model when the source is ideal

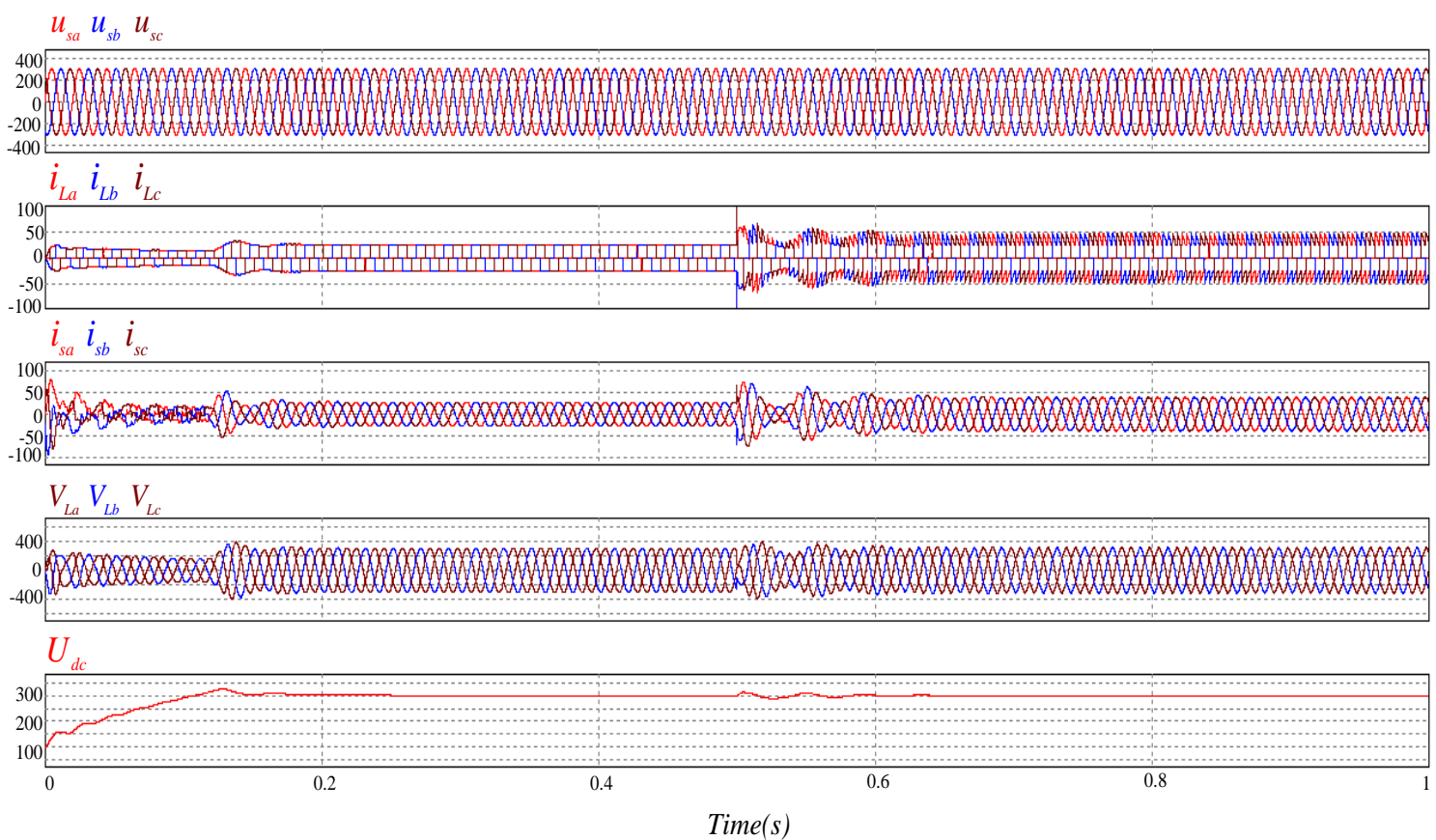

Figure 8. Waveforms of the model with a two-level voltage source inverter when the source is ideal

When the three-phase source voltage is not ideal (distortion and unbalance): the source voltage amplitude of phase $a$ is greater than the voltage amplitude of phase $b$ and $c$ and the THD of phase $a$ is greater than THD of phase $b$ and $c$. THD\% of non-ideal source voltage is shown in Figure 9. When the source voltage is unbalanced and distorted, we have the waveforms of the integrated compensation model using a three-level NPC inverter shown in Figure 10 and the integrated compensation model using the two-level voltage source inverter is shown in Figure 11. 


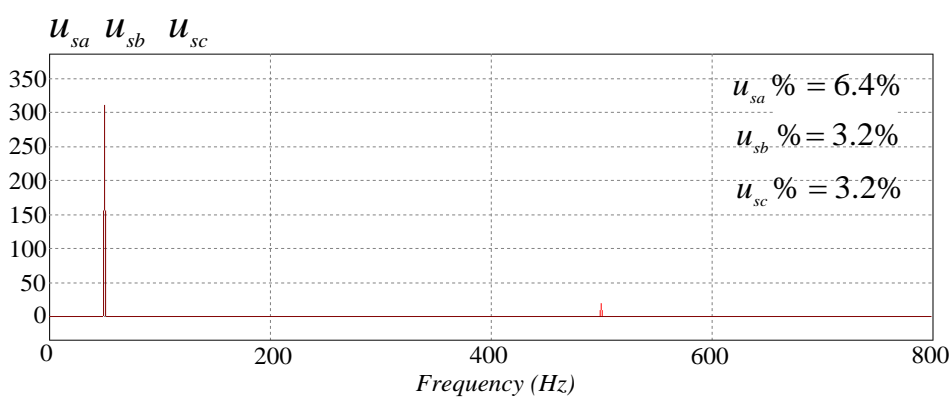

Figure 9. THD\% of non-ideal source voltage

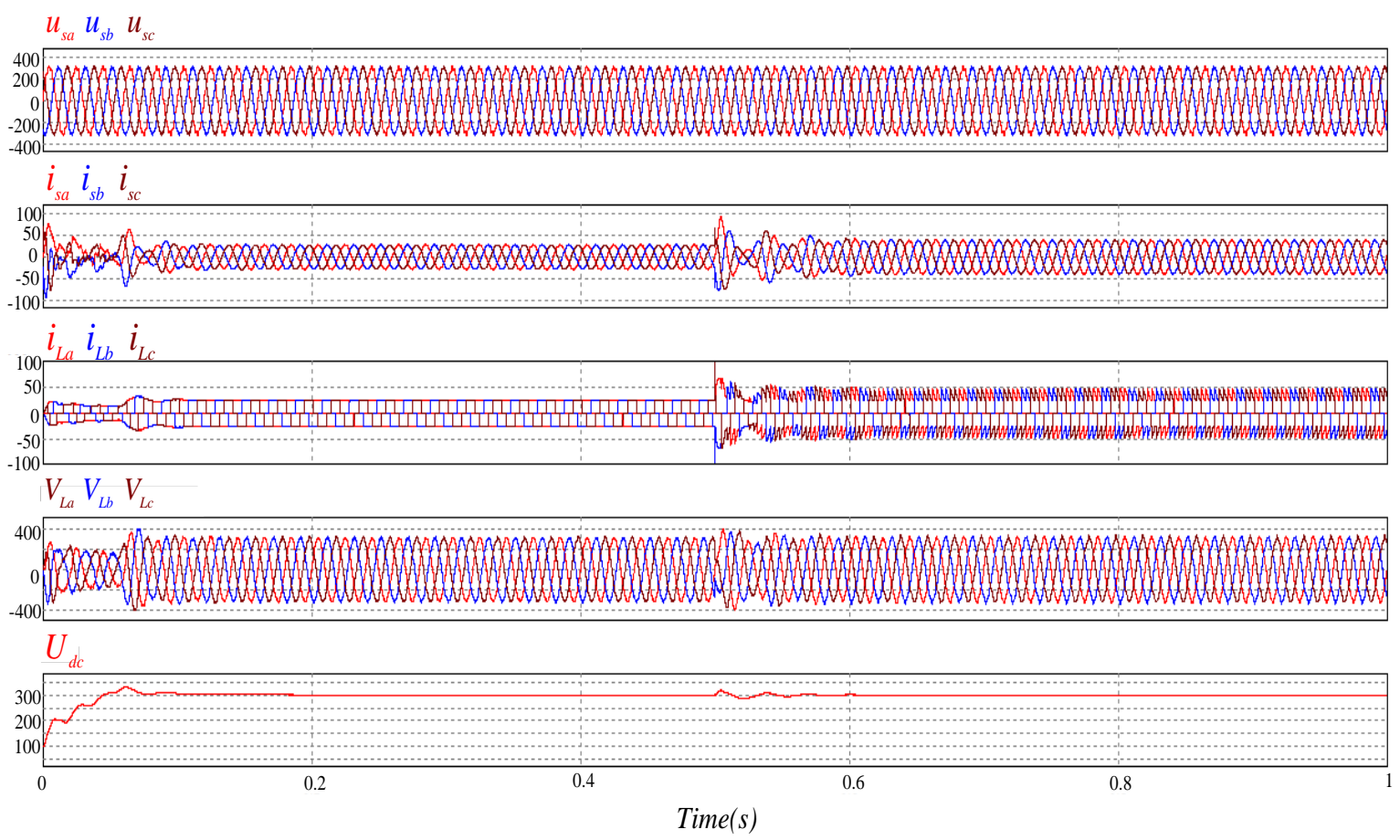

Figure 10. Waveforms of the proposed model when the source voltage is unbalanced and distorted

From Figure 10 we can see that: before the load changed, the three-phase supply currents have THD $\%$ values: $\mathrm{THD} i_{s a} \%=1.9 \%, \mathrm{THD}_{s b} \%=1.8 \%$ and $\mathrm{THD} i_{s c} \%=1.8 \%$. THD $\%$ of the source voltages applied to the load are $\operatorname{THD} v_{L a} \%=3.1 \%, \mathrm{THD}_{L b} \%=2.9 \%$ and $\mathrm{THDv}_{L c} \%=2.9 \%$. When the load changes in the direction of increasing THD, the THD\% of the three-phase supply currents are $\mathrm{THD} i_{s a} \%=2.5 \%$, $\mathrm{THD} i_{s b} \%=2.3 \%$ and $\mathrm{THD} i_{s c} \%=2.3 \%$. THD $\%$ of load voltages are $\mathrm{THD} v_{L a} \%=4.5 \%, \mathrm{THD} v_{L b} \%=4.2 \%$ and $\mathrm{THD} v_{L c} \%=4.2 \%$. DC-bus voltage reaches of $300 \mathrm{~V}$ at $0.07 \mathrm{~s}$ before load changed and at $0.04 \mathrm{~s}$ after the load changed.

From Figure 11 we can see that: before the load changed, the three-phase supply current has THD\% value: $\mathrm{THD} i_{s a} \%=2.1 \%, \mathrm{THD}_{s b} \%=2.0 \%$ and $\mathrm{THD} i_{s c} \%=2.0 \%$. THD $\%$ of source voltages applied to the load are $\mathrm{THD} v_{L a} \%=3.5 \%, \mathrm{THD} v_{L b} \%=3.3 \%$ and $\mathrm{THD} v_{L c} \%=3.3 \%$. When the load changes in the direction of increasing THD, the THD $\%$ of the three-phase supply currents are $\mathrm{THD} i_{s a} \%=4.6 \%$, $\mathrm{THD} i_{s b} \%=4.2 \%$ and $\mathrm{THDi}_{s c} \%=4.2 \%$. THD $\%$ of voltages applied to the load are: $\mathrm{THD} v_{L a} \%=4.8 \%$, $\mathrm{THD} v_{L b} \%=4.6 \%$ and $\mathrm{THD} v_{L c} \%=4.6 \%$, DC-bus voltage reaches the set of $300 \mathrm{~V}$ at $0.2 \mathrm{~s}$ before load changes and $0.04 \mathrm{~s}$ after when the load changes. From the simulation results, we can see that: the integrated compensation model using a three-level NPC inverter is more effective when using a two-level voltage source inverter in stabilizing DC-bus voltage and minimum the supply current total harmonic distortion, minimum the voltage total harmonic distortion applied to the load. 


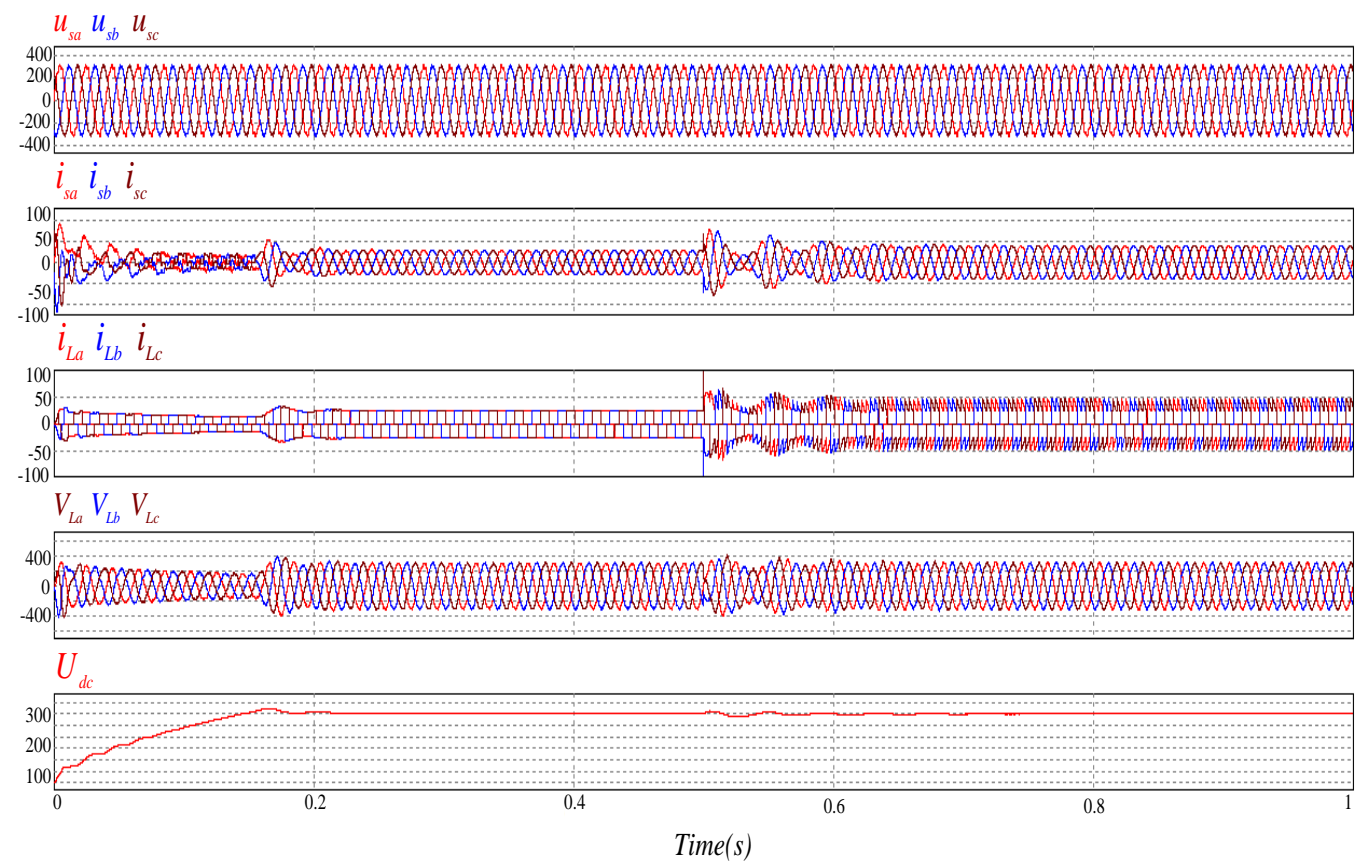

Figure 11. Waveforms of the model using a two-level voltage source inverter when the source voltage is unbalanced and distorted

\section{CONCLUSION}

This paper introduced a three-phase integrated compensation model for different types of harmonic sources using a three-phase NPC inverter. First, the mathematical model of model is analyzed and then the simulation cases: ideal source and non-ideal, load is changed. As a result, the supply current and source voltage applied to the load always achieve sinusoidal waveform with a distortion is very low. Compared to the traditional integrated compensation model using a two-level voltage source inverter, the simulation results have demonstrated the effectiveness of the proposed integrated compensation model in stabilization DC-bus voltage, minimum total harmonic distortion of supply current and voltage applied to the load.

\section{REFERENCES}

[1] Sushree Diptimayee Swain, et al., "Design of Passive Power Filter for Hybrid Series Active Power Filter using Estimation, Detection and Classification Method," Int. J. Emerg. Electr. Power Syst, vol. 17, no. 3, pp. 363-375, 2016.

[2] Amol Anandrao Patil, et al., "Harmonic metigation using Passive Filter," International Journal of Engineering Trends and Technology, vol. 45, no. 2, pp. 83-86, 2017.

[3] D. A. A. Osman, et al., "Development of active power filter using rectifier boost technique," International Journal of Power Electronics and Drive System (IJPEDS), vol. 10, no. 3, pp. 1446-1453, 2019.

[4] C. Madtharad and S. Premrudeepreechacharn, "Active power filter for three-phase four-wire electric systems using neural networks,” Elect. Power Syst. Res., vol. 60, issue 3, pp. 179-192, 2002.

[5] Bachar Rahima, et al., "High-performance active power filter implementation based on predictive current control," International Journal of Power Electronics and Drive System (IJPEDS), vol. 10, no. 1, pp. 277-287, 2019.

[6] Ab. Hamadi, et al., "A new hybrid series active filter configuration to compensate voltage sag, swell, voltage and current harmonics and reactive power," IEEE International Symposium on Industrial Electronics, pp. 286-291, 2009.

[7] Liqing Tong, et al., "A novel series-in series hybrid active power filter," Twenty-Third Annual IEEE Applied Power Electronics Conference and Exposition, pp. 1874-1878, 2008.

[8] Muftah Abuzied, et al., "Sliding Mode Control of Three-Phase series Hybrid Power Filter with Reduced cost and Rating," IECON 44th Annual Conference of the IEEE Industrial Electronics Society, pp. 1495- 1500, 2018.

[9] Abdelmalek Meftouhi, et al., "PV integrated series active filter for sag voltage andharmonic compensation," International Journal of Power Electronics and Drive System (IJPEDS), vol. 10, no. 3, pp. 1255-1262, 2019.

[10] Bartosz Kedra, "Comparison of an active and hybrid power filter devices," $16^{\text {th }}$ International Conference on Harmonics and Quality of Power (ICHQP), pp. 556-560, 2014. 
[11] Abdallah B. A, et al., "A comparative study and experimental validation on single phase series active power filter control strategies using PI, FLC and sliding mode controllers," International Journal of Power Electronics and Drive System (IJPEDS), vol. 10, no. 2, pp. 731-743, 2019.

[12] Salmeron P and Litran S P, "A control strategy for hybrid power filter to compensate four-wires three-phase systems," IEEE Trans Power Electron, vol. 25, no. 7, pp. 1923-1931, 2010.

[13] Tian J, et al., "Series hybrid active power filter based on controllable harmonic impedance," IET J Power Electron, vol. 5, no. 1, pp. 142-148, 2012.

[14] N. R. Kudithi, S. Somkun, "Single Phase Power Generation System from Fuel Cell," International Journal of Power Electronics and Drive System (IJPEDS), vol. 9, no. 4, pp. 1676-1684, 2018.

[15] Minh Thuyen Chau, "Adaptive Current Control Method for Hybrid Active Power Filter," Journal of Electrical Engineering. vol. 67, issue 5, pp. 343-350, 2016.

[16] Akagi H, et al., "Instantaneous Power Theory and Applications to Power Conditioning," IEEE Press, New Jersey, 2007.

[17] Chau Minh Thuyen, "Improved p-q Harmonic Detection Method for Hybrid Active Power Filter," International Journal of Electrical and Computer Engineering (IJECE). vol. 8, no. 5, pp. 2910-2919, 2018.

[18] Chau Minh Thuyen, "A new design algorithm for Hybrid Active Power Filter," International Journal of Electrical and Computer Engineering (IJECE). vol. 9, no. 6, pp. 4507-4515, 2019.

[19] Soumya Ranjan Das, "Fuzzy Sliding Mode Based Series Hybrid Active Power Filter for Power Quality Enhancement," Advances in Fuzzy Systems, vol. 2018, pp. 1-8, 2018.

[20] Huayun Yang, et al., "A practical series hybrid active power filter based on fundamental magnetic potential selfbalance," 2006 International Conference on Power System Technology, 1-6, 2006.

[21] Madhu B. R, et al., "Design of Shunt Hybrid Active Power Filter to Reduce Harmonics on AC Side Due to Non-linear Loads," International Journal of Power Electronics and Drive System (IJPEDS), vol. 9, no. 4, pp. 1926-1936, 2018.

[22] Chau Minh Thuyen, "A New Approach in Design for Hybrid Active Power Filter," ICIC Express Letters, vol. 12, no. 9, pp. 897- 904, 2018.

[23] Moh. Jauhari, et al., "Control Design for Shunt Active Power Filter Based on p-q Theory in Photovoltaic GridConnected System," International Journal of Power Electronics and Drive System (IJPEDS), vol. 10, no. 3, pp. 1064-1071, 2019.

[24] IEEE Recommended Practices and Requirements for Harmonic Control in Electrical Power Systems, IEEE Std 519-1992, pp.1-112, 9 April 1993

[25] Chau Van Bao and Chau Minh Thuyen, "DC-Bus Voltage Stabilization of Hybrid Active Power Filter," ICIC Express Letters, vol. 13, no. 1, pp. 27-33, 2019.

\section{BIOGRAPHIES OF AUTHORS}

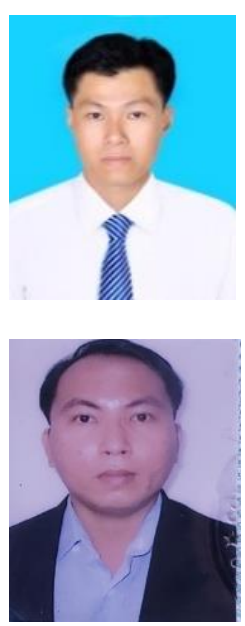

Chau Minh Thuyen was born in Binh Dinh, Vietnam, on June 6, 1977. He received his B.S. and M.S. from the Da Nang University of Technology, Da Nang, Viet Nam, and the University of Technical Education Ho Chi Minh City, Ho Chi Minh City, Viet Nam, in 2001 and 2005, respectively, and Ph.D. from Hunan University, Changsha, China, in 2012., Since 2004, he has been a Lecturer at Industrial University of Ho Chi Minh City, Viet Nam. His current research interests include electric power savings, reactive power compensation, and active power filters.

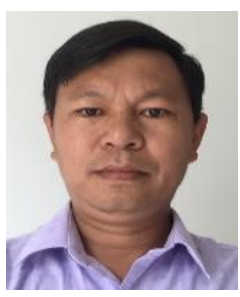

Nguyen Hoai Thuong, Ph.D in Condensed Matter Physics. He was born in 1986, finished Bachelor and Master's programs in Volgograd State Technical University (Russia) and Ph.D in Voronezh State University (Russia). He works in Faculty of Electrical Engineering Technology, Industrial University of Ho Chi Minh City, Vietnam. The research interests focus on fabrication of multifunctional materials applied in electrical and electronics engineering technology. Up to now, he has contributed to the field with 38 articles published in ISI-ranked journals.

Truong Khac Tung received his B.S. in Mathematics from Hue University's college of education, Vietnam, in 2001. He received M.S. in computer science from Hue University of Sciences, Vietnam, in 2007. He received a Ph.D. degree in computer science at the College of Information Science and Engineering, Hunan University, China in 2013. He is currently a lecturer at the Faculty of Information Technology, Industrial University of HCM city. His current research interests include soft computing, operational research, and artificial intelligence. 